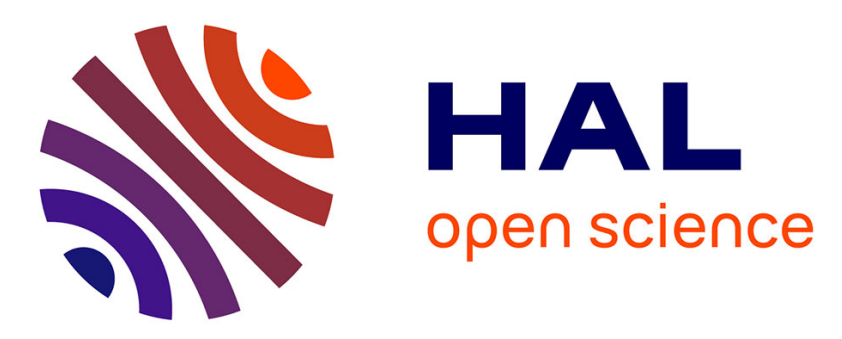

\title{
Electrochemical Performance and Mechanism of Calcium Metal-Organic Battery
}

Jan Bitenc, Antonio Scafuri, Klemen Pirnat, Matic Lozinšek, Ivan Jerman, Jože Grdadolnik, Bernard Fraisse, Romain Berthelot, Lorenzo Stievano, Robert Dominko

\section{To cite this version:}

Jan Bitenc, Antonio Scafuri, Klemen Pirnat, Matic Lozinšek, Ivan Jerman, et al.. Electrochemical Performance and Mechanism of Calcium Metal-Organic Battery. Batteries \& Supercaps, 2020, 4 (1), pp.214-220. 10.1002/batt.202000197 . hal-03001521

\section{HAL Id: hal-03001521 \\ https://hal.science/hal-03001521}

Submitted on 6 Jan 2021

HAL is a multi-disciplinary open access archive for the deposit and dissemination of scientific research documents, whether they are published or not. The documents may come from teaching and research institutions in France or abroad, or from public or private research centers.
L'archive ouverte pluridisciplinaire HAL, est destinée au dépôt et à la diffusion de documents scientifiques de niveau recherche, publiés ou non, émanant des établissements d'enseignement et de recherche français ou étrangers, des laboratoires publics ou privés. 


\title{
Case-study of a Rechargeable Calcium Metal Anode- Organic Polymer Cathode Battery
}

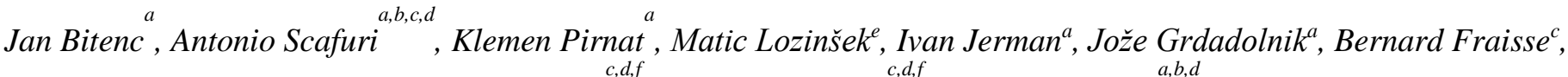 \\ Romain Berthelot $^{c, d, f}$, Lorenzo Stievano ${ }^{c, d, f}$, Robert Dominko ${ }^{a, b, c}$ \\ ${ }^{a}$ National Institute of Chemistry, Hajdrihova 19, 1000 Ljubljana, Slovenia \\ ' Faculty for Chemistry and Chemical Technology, University of Ljubljana, Večna pot 113, Ljubljana, Slovenia \\ ICGM, Université de Montpellier, CNRS, Montpellier, France \\ d Alistore-European Research Institute, CNRS FR 3104, Hub de l'Energie, Rue Baudelocque, 80039 Amiens, France \\ eJožef Stefan Institute, Jamova 39, 1000 Ljubljana, Slovenia \\ fRéseau sur le Stockage Electrochimique de l'Energie (RS2E), CNRS, Amiens, France
}

\begin{abstract}
The recent development of novel Ca electrolytes has enabled the application of $\mathrm{Ca}$ metal anode in Ca rechargeable batteries. However, the actual performance of inorganic cathode materials in these systems is still mediocre, and only the application of alternative more efficient positive electrodes, such as organic cathodes, can accelerate their further development. Herein, we present the case-study of an antraquinone-based polymer that shows good reversibility and high capacity when used as the cathode active material in Ca batteries. The electrochemical mechanism involves the reduction of the carbonyl groups of anthraquinone during the discharge, as confirmed by ex situ ATR-IR. EDS spectroscopy reveals that the reduced organic groups are mostly coordinated with $\mathrm{Ca}^{2+}$ ions and a small amount of not fully dissociated $\mathrm{Ca}\left[\mathrm{B}(\mathrm{hfip})_{4}\right]^{+}$monovalent cations, which holds promise for the practical realization of high-energy density Ca metal-organic batteries. Long term cyclability is affected by an overpotential increase connected with the Ca stripping process at the metal anode, confirming the need for further research on $\mathrm{Ca}$ electrolytes with improved chemical compatibility with $\mathrm{Ca}$ metal.
\end{abstract}

Keywords: Calcium; metal battery; organic cathode; hexafluoroisopropylborate; electrochemical mechanism,

\section{Introduction}

Currently, Li-ion batteries (LIB) are dominating the market of battery technologies with their applications ranging from portable electronics, electric vehicles to stationary energy storage. Their high energy density, long-cycle life, low self-discharge and versatility make them preferable over other state-of-the-art battery technologies. However, the ever-increasing demand for energy storage is raising concerns about the availability and sustainability of the materials used for Li-ion cells production. ${ }^{[1-3]}$ Therefore, research groups are actively pursuing new battery technologies with an aim of lowering the cost of batteries and at the same time offering commercially attractive electrochemical properties based on abundant materials. ${ }^{[4]}$ This is by far not trivial and requires material development of all battery components (electrolyte, electrodes, etc.). The most likely scenario 
is that no silver bullet technology will replace LIB in all applications, but adapted alternative systems will be created for specific applications, significantly lowering the demand on the limited raw materials used in LIB.

Among the most intriguing alternative battery systems are multivalent-ion batteries, especially batteries based on $\mathrm{Ca}, \mathrm{Mg}$ and $\mathrm{Al}$. These elements belong all among the ten most abundant ones on Earth's crust. ${ }^{[5]}$ Their application is especially interesting due to the high volumetric and gravimetric energy densities of their metal anodes, and indications that these metals might be less prone to dendrite formation as Li metal. ${ }^{[6,7]}$ The downside of multivalent metals is their redox potential which is considerably higher than that of Li metal. If we presume that the cathode potential does not change, we can expect the voltage of the battery cells to decrease by $1.4,0.7$ and $0.2 \mathrm{~V}$ when moving from $\mathrm{Li}$ to $\mathrm{Al}, \mathrm{Mg}$ and $\mathrm{Ca}$ metal anode, respectively. While the difference in redox potential is the most favourable for Ca metal, its feasibility has been until recently hindered by the lack of suitable electrolytes. The main issue of Ca electrolytes is their electrochemical stability in contact with Ca metal. There are mainly two approaches to tackle this issue: (i) the formation of a passivation layer on Ca metal permeable to $\mathrm{Ca}^{2+}$ ions by limited decomposition of a metastable electrolyte, or (ii) use of electrolytes that do not form passivating layer. ${ }^{[8]}$

Although Ca deposition/stripping was demonstrated using $\mathrm{Ca}\left(\mathrm{AlCl}_{4}\right)_{2}$ in $\mathrm{SOCl}_{2}$ already in 1980 , the Coulombic efficiency was found to be low and the corrosion of $\mathrm{Ca}$ was an evident problem. ${ }^{[9]}$ Significant progress was accomplished by using $\mathrm{Ca}\left(\mathrm{BF}_{4}\right)_{2}$ salt in the mixture of ethylene carbonate and propylene carbonate solvents, which enabled $\mathrm{Ca}$ deposition/stripping with improved Coulombic efficiency, even though only at elevated temperatures. ${ }^{[10]}$ A breakthrough at ambient temperature was recently achieved using $\mathrm{Ca}\left(\mathrm{BH}_{4}\right)_{2}$ and $\mathrm{Ca}\left[\mathrm{B}(\mathrm{hfip})_{4}\right]_{2}$ ([B(hfip) 4$]$ - calcium hexafluoroisopropylborate) dissolved in ethereal solvents. ${ }^{[1-13]}$ Although these studies exemplified significant progress for application of $\mathrm{Ca}$ metal anodes, the Coulombic efficiency still has to be increased and the passivation process on the surface of $\mathrm{Ca}$ metal better understood for practical applications. Only then can the high volumetric $\left(2073 \mathrm{mAh} / \mathrm{cm}^{3}\right)$ and gravimetric $(1337 \mathrm{mAh} / \mathrm{g})$ capacity of Ca metal anode be utilized in real battery cells. $\mathrm{Ca}^{2+}$ ion is a unique cation: it is bivalent like $\mathrm{Mg}^{2+}$, but its ionic radius is more similar to $\mathrm{Na}^{+}$, which could mean that the $\mathrm{Ca}^{2+}$ ion exhibits similar site preference. ${ }^{[8]}$ There were several attempts to intercalate $\mathrm{Ca}^{2+}$ in different inorganic phases, but the electrochemical performance has always been quite far from full reversibility. ${ }^{[14-16]}$ Hence, we propose here a radically different approach, i.e., the use of organic cathode materials. Organic electrodes offer electrochemical activity with a multitude of cations with various sizes and charges. ${ }^{[17]}$ Reversible electrochemical performance of organic moieties was already demonstrated in various metal-organic batteries including Li, $\mathrm{Na}, \mathrm{K}, \mathrm{Mg}, \mathrm{Zn}$ and $\mathrm{Al} .{ }^{[18-23]}$ Organics can be also produced from sustainable materials and at lower synthesis temperatures, which should help to lower the carbon footprint of battery production. ${ }^{[24]}$ One of the major downsides of organic compounds is their solubility in electrolyte solutions. The most effective approach for tackling dissolution is the preparation of polymers. Chemical binding of electroactive groups results in an increase of molecular weight, which decreases solubility. Polymerization typically requires a molecular linker, which leads to the increase of the atomic mass per electroactive group. If the molecular linker is small, the decrease in capacity is acceptable. ${ }^{[18]}$ The volumetric capacity of organic electrodes is considerably lower than that of inorganic ones, but this disadvantage can be effectively compensated by the high volumetric capacity of the Ca metal anode.

There is a plethora of different organic electrode materials that can operate in different ways: through reduction and storage of cations (n-type), oxidation and storage of anions (p-type) or via both mechanisms, being able to reduce and oxidize (bipolar) at the same time. N-type organic cathode materials are the most practical cathode material for metal anodes, because only storage of metal cations will allow operating in lean electrolyte conditions inside real battery cells. Among such materials, conjugated carbonyl materials exhibit high capacity, 
good reversibility and long-term stability in several different metal-organic systems. ${ }^{[23,25,26]}$ Anthraquinone-based materials often serve as model compounds due to their availability, relatively straightforward polymerization and the fact that their redox potential fits well within the voltage stability window of most battery electrolytes. Hence, electrochemical performance and electrochemical mechanism of anthraquinone-based compounds have already been studied in $\mathrm{Mg}$ and $\mathrm{Al}$ battery system. ${ }^{[21,23]}$ So far organic materials based on conjugated organic carbonyl compounds have been tested exclusively in aqueous Ca electrolytes. ${ }^{[27,28]}$ Here poly(anthraquinonyl sulfide) (PAQS) is tested against a $\mathrm{Ca}$ metal anode using a state-of-the-art non-aqueous $\mathrm{Ca}$ electrolyte based on $\mathrm{Ca}[\mathrm{B} \text { (hfip) }]_{2}$ in DME (dimethoxyethane). Its electrochemical performance was investigated in two and three electrodes laboratory cells to distinguish electrode overpotentials. Electrochemical mechanism of organic moiety during $\mathrm{Ca}$ cation coordination/decoordination was investigated through ex situ IR spectroscopy and energy dispersive spectroscopy (EDS) to determine the speciation of $\mathrm{Ca}$ cations $\left(\mathrm{Ca}^{2+}\right.$ and $\left.\left[\mathrm{CaB}(\mathrm{hfip})_{4}\right]^{+}\right)$that counterbalance the negative charge on the reduced anthraquinone groups.

\section{Results and discussion}

The first and necessary requirement for the realization of $\mathrm{Ca}$ metal-organic battery is an efficient $\mathrm{Ca}$ electrolyte, which enables Ca stripping/deposition with relatively low overpotential and high reversibility. The synthesized $\mathrm{Ca}[\mathrm{B} \text { (hfip) }]_{2} \times 4 \mathrm{DME}$ salt was carefully characterized with a multitude of analytical techniques. ${ }^{1} \mathrm{H}$ and ${ }^{13} \mathrm{C}$ NMR show that $\mathrm{Ca}\left(\mathrm{BH}_{4}\right)_{2} \times 2 \mathrm{THF}$ and hexafluoroisopropanol (HFIP) reacted completely and that no residue of HFIP can be detected in the spectra (Figure S1). Both single crystal and powder XRD (Figure S2) analyses of the salt are in good agreement with the literature crystallographic data. ${ }^{[12,13]}$ ATR-IR allowed us also to identify several characteristic bands for the salt anion belonging to $\mathrm{C}-\mathrm{CF}_{3}, \mathrm{~B}-\mathrm{O}-\mathrm{C}, \mathrm{C}-\mathrm{O}$ stretching and $\mathrm{CF}_{3}$ deformation modes (Figure S3). All other salt characterization techniques are discussed in more details in SI and support our conclusion regarding the successful synthesis of $\mathrm{Ca}\left[\mathrm{B}(\mathrm{hfip})_{4}\right]_{2} \times 4 \mathrm{DME}$ (Figure S4).

However, it is important to note that the dissolution of the prepared salt resulted in solutions with a slight white turbidity. Such behavior can be attributed to the purity of the starting compound, $\mathrm{Ca}\left(\mathrm{BH}_{4}\right)_{2} \times 2 \mathrm{THF}$, caused by the existence of different $\mathrm{Ca}\left(\mathrm{BH}_{4}\right)_{2}$ polymorphs with varying degrees of solubility. ${ }^{[29]}$ Similar white turbidity was also observed when preparing the analogous $\mathrm{Mg}$ salt, $\mathrm{Mg}\left(\mathrm{B}(\mathrm{hfip})_{4}\right)_{2}$ using commercial $\mathrm{Mg}\left(\mathrm{BH}_{4}\right)_{2} .^{[30]}$ Nevertheless, in both cases no significant difference could be observed in the electrochemical performance from the already published results. ${ }^{[12,13]}$ Stripping and deposition of our electrolyte was assessed through cyclic voltammetry $(\mathrm{CV})$ on a stainless steel electrode (Figure 1). As can be seen from CV curves, there is an activation in the initial cycles, which is connected with the fact that the 2-electrode cell is utilized and overpotential contribution from $\mathrm{Ca}$ counter electrode has to be taken into account. Lack of additional anodic peaks shows that the electrolyte has good oxidative stability and should enable the testing of cathode materials in the voltage window between 1.3 and 3.3V vs. Ca metal. Coulombic efficiency of the Ca stripping increases from an initial $53 \%$ up to $67 \%$, where it stabilizes. Decrease in Coulombic efficiency from literature reports ${ }^{[12,13]}$ could be attributed to move from noble metal electrodes to the stainless steel working electrode and change in electrochemical setup. Current Coulombic efficiency is suitable for proof-of-concept testing on lab scale, but in real cells metal stripping/deposition efficiencies higher than $99.9 \%$ are to be targeted. 

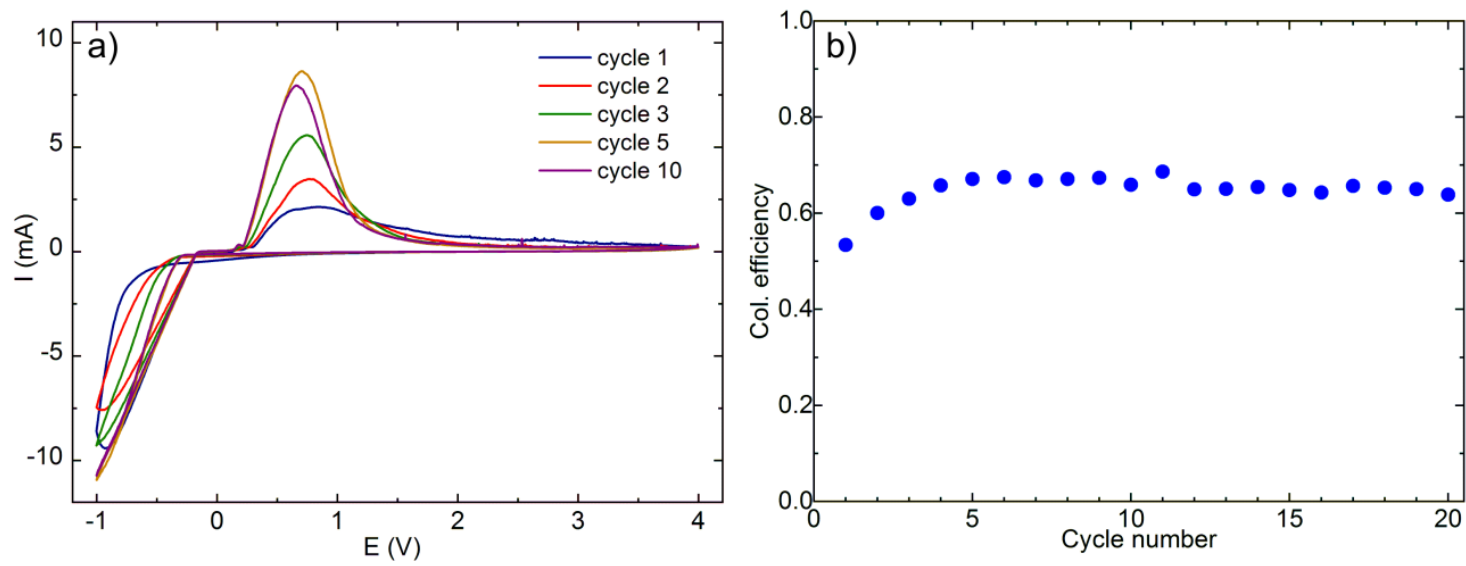

Figure 1: a) Selected cycles of cyclic voltammetry of $0.3 \mathrm{M} \mathrm{Ca}\left[\mathrm{B}(\mathrm{hfip})_{4}\right]_{2}$ in DME on stainless steel electrode in the voltage window from -1.0 to $4.0 \mathrm{~V}$ with a sweep rate of $25 \mathrm{mV} / \mathrm{s}$. b) Coulombic efficiency of Ca stripping/deposition during corresponding cyclic voltammetry test.

After confirming the reversibility of Ca deposition/stripping process, our electrolyte could be used to test the organic cathode. Anthraquinone based polymer PAQS, having so far displayed reversible electrochemical activity in $\mathrm{Mg}$ and $\mathrm{Al}$ electrolytes, ${ }^{[21,23]}$ was chosen as a model organic electrode material. First tests with the plain polymer displays low activity, with only approximately $20 \%$ of the theoretical capacity utilized with a relatively high polarization at a low current density of $0.2 \mathrm{C}$ (Figure S5). To improve its performance, PAQS was polymerized in a suspension of carbon nanotubes (CNTs) giving a nanostructured PAQS/CNTs composite that was then used as an active material. SEM (Figure 2a-b) shows that the polymer is well interconnected with CNTs and displays a highly porous structure. PAQS/CNTs cathode delivered a first discharge capacity of $169.3 \mathrm{mAh} / \mathrm{g}$ (Figure 2c), which is $75 \%$ of the theoretical one $(225 \mathrm{mAh} / \mathrm{g})$, confirming a significant improvement due to nanostructurization of polymer with CNTs. The discharge in the first plateau is different from the subsequent cycles, a feature previously observed in other multivalent electrolytes. ${ }^{[21,23]}$ In the second cycle, the discharge plateau becomes less inclined and was upshifted to an average discharge voltage of $2.1 \mathrm{~V}$. The overpotential started to increase in the following cycles and the average discharge plateau in the $5^{\text {th }}$ cycle was at $1.9 \mathrm{~V}$. In contrast, the increase of the overpotential is much smaller during charge. The increase of the overpotential is also accompanied with an increase of the voltage dip at the beginning of the discharge half cycle (Figure 2d). At the start of the first discharge there is only a short sharp peak, but this peak evolves and becomes both deeper and longer with cycling. This phenomenon can be related to the increase of the overpotential for Ca stripping at the Ca metal anode, which takes place during the discharge, as shown in Figure 3. Such an increase in overpotential results in a significant decrease of the cathode capacity from $169.3 \mathrm{mAh} / \mathrm{g}$ in the first cycle down to $112.3 \mathrm{mAh} / \mathrm{g}$ in the $6^{\text {th }}$ cycle (Figure 2e). In the following cycles, polarization increases even further and a capacity lower than $10 \mathrm{mAh} / \mathrm{g}$ is obtained. Coulombic efficiency is relatively high until a drastic drop of the capacity, which is connected with a strong increase in polarization. 

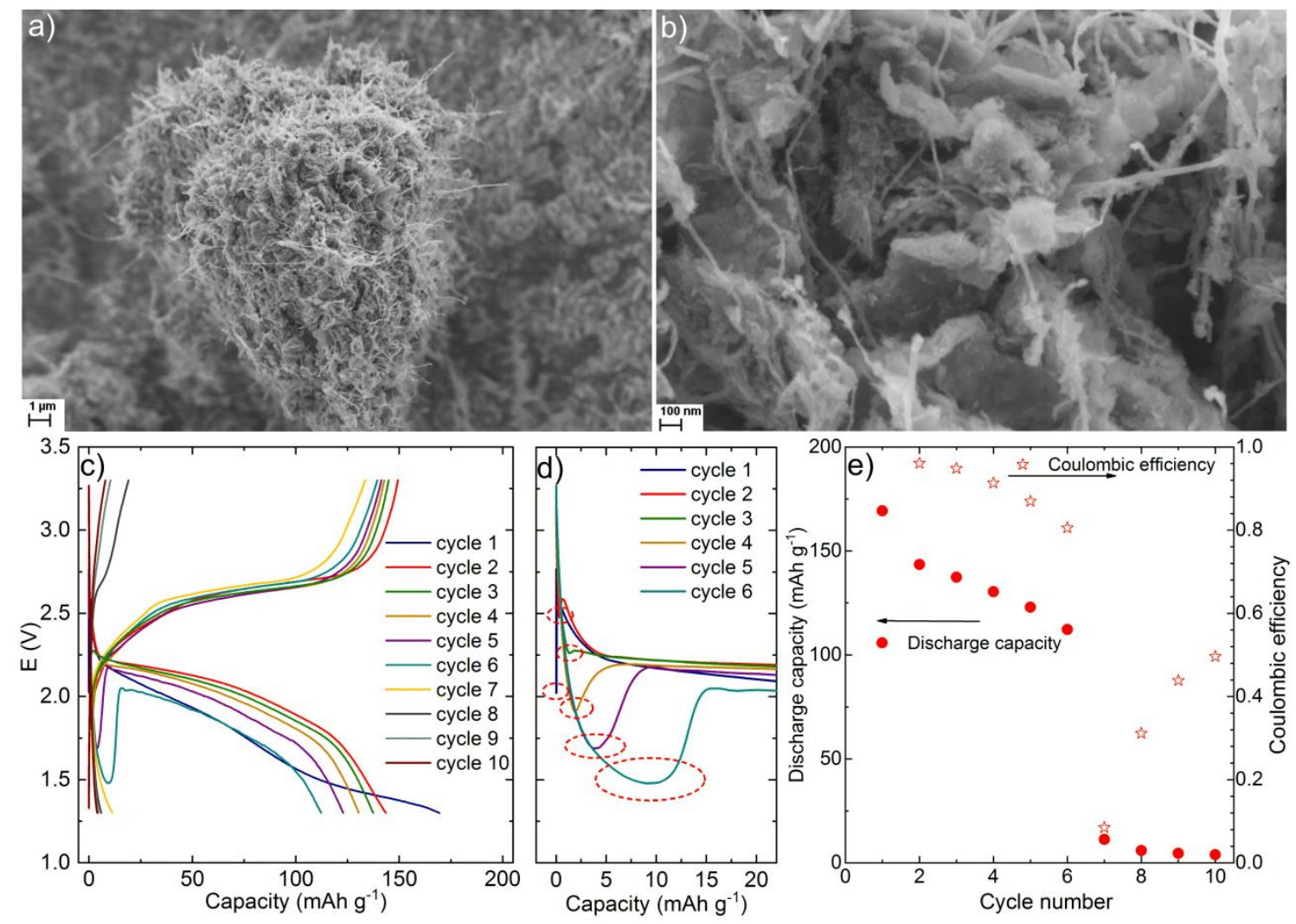

Figure 2: a and b) Scanning electron micrographs of PAQS/CNTs composite. c) Galvanostatic cycles of Ca metal-PAQS/CNTs battery cell at $0.5 \mathrm{C}$ in the voltage window from 1.3 to $3.3 \mathrm{~V}$. d) Inset into the start of the discharge curve for first five cycles. Voltage axis is same as on c part of figure, voltage dips are circled with red dash circle. e) Corresponding discharge capacity and Coulombic efficiency for the Ca metalPAQS/CNTs battery cell.

Tests in a 3-electrode cell with a Ca metal reference electrode were performed to verify the hypothesis that calcium anode is causing increased polarization (overpotential) and consequent cell failure in a two electrode cell. The first important difference is the absence of a voltage dip at the start of the discharge in the half-cell between working electrode (cathode) and reference electrode, and a well-defined overpotential increase at the start of the Ca stripping from the $\mathrm{Ca}$ anode (Figure 3a). The starting overpotential for Ca stripping gradually increases, as suggested by the results in the 2-electrode cell (Figure 3b). This has important implications also for the future energy efficiency of such cells since energy losses are increasing both through an increase of overpotential and increase of the time that this overpotential is present during discharge of the full cell. After the initial peak, the overpotential for $\mathrm{Ca}$ stripping from $\mathrm{Ca}$ anode is around $0.05 \mathrm{~V}$. The overpotential for Ca deposition is several times larger, around $-0.30 \mathrm{~V}$ versus the reference electrode and remains stable during cycling. The capacity fade is also significantly smaller than in the 2-electrode cell, but still present (Figure 3c). After 10 cycles, a capacity of $114.2 \mathrm{mAh} / \mathrm{g}$ is obtained, confirming that both the capacity fade at the cathode and the increase of the overpotential at the $\mathrm{Ca}$ anode are responsible for the fast capacity decay in the 2-electrode cell, with a larger contribution of the latter. Most likely, the increase of overpotential at the $\mathrm{Ca}$ anode is connected with the accumulation of $\mathrm{CaF}_{2}$ on the $\mathrm{Ca}$ metal anode. The formation of $\mathrm{CaF}_{2}$ along with the deposition of $\mathrm{Ca}$ metal was already observed in previous reports on $\mathrm{Ca}\left[\mathrm{B}(\text { hfip })_{4}\right]_{2}$ electrolytes, ${ }^{[12,13]}$ confirming the need for further development of such $\mathrm{Ca}$ electrolytes to meet long-term cycling performance of Ca metal anodes. 

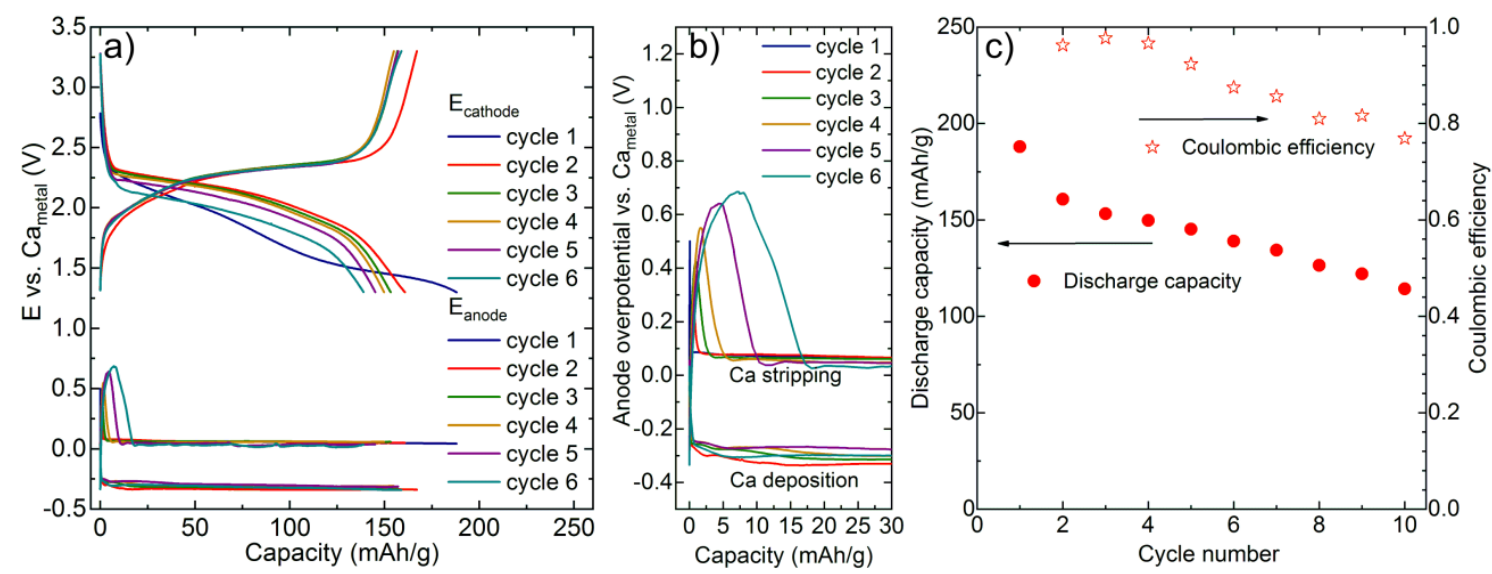

Figure 3: a) Galvanostatic cycling of $\mathrm{Ca}$ metal-PAQS/CNTs cell with Ca reference electrode at $0.5 \mathrm{C}$. The top curves show the potential of PAQS/CNTs cathode, while the bottom curves show the potential of Ca metal anode. Part of $\mathrm{Ca}$ metal anode potential over $\mathrm{O} \mathrm{V}$ corresponds to Ca stripping process and part below $0 \mathrm{~V}$ to Ca deposition process. b) Inset into starting part of anode overpotential, where increase of overpotential occurs. c) Discharge capacity and Coulombic efficiency during cycling in 3-electrode cell.

The efficient electrochemical reaction of PAQS with calcium ions can be confirmed by studying its reaction mechanism. In the case of conjugated carbonyl compounds, we expect the reversible reduction of the carbonyl to conjugated alkoxy group with the addition of one electron per carbonyl group if full theoretical capacity is utilized (Figure 4a). This change can be followed by infrared spectroscopy, with the decrease in intensity of the carbonyl band upon discharge and the simultaneous appearance of new band representing the conjugated alkoxy group. ${ }^{[31]}$ To observe PAQS electrochemical mechanism, we prepared three ex situ electrodes. One electrode was only soaked in electrolyte and washed (as a reference for the washing procedure), while the other two were cycled (one discharged, while the other was discharged and then charged). Soaking of the electrode in the electrolyte did not cause any major changes (Figure 4b). Very low intensity bands were observed in the region between 1100 and $1000 \mathrm{~cm}^{-1}$, which could be attributed to incomplete washing of the electrolyte and could be assigned to $\mathrm{C}-\mathrm{O}$ stretching modes. Spectrum of the discharged electrode displayed completely different bands and looked relatively noisy. The $\mathrm{C}=\mathrm{O}$ double band at 1674 and $1650 \mathrm{~cm}^{-1}$, the $\mathrm{C}-\mathrm{C}$ stretching at $1570 \mathrm{~cm}^{-1}$ and the $\mathrm{C}-\mathrm{H}$ out of plane bending at $704 \mathrm{~cm}^{-1}$, which are characteristic of the PAQS polymer, disappeared, while a new band at $1374 \mathrm{~cm}^{-1}$ was observed, which can be assigned to the alkoxy conjugated groups and is consistent with previous observations in reduced monovalent $(\mathrm{Li})^{[31]}$ and bivalent $(\mathrm{Mg})^{[32]}$ anthraquinone salts. Even though this band is relatively broad and is close to the $\mathrm{C}-\mathrm{CF}_{3}$ stretching band belonging to salt anion, its observed downshift indicates that both vibrational modes contribute to this band. Several additional bands in the region between 1200 and $1000 \mathrm{~cm}^{-1}$ were observed, together with a very intense $\mathrm{C}-\mathrm{F}$ vibration band at $686 \mathrm{~cm}^{-1}$ that can be confused for downshifted $\mathrm{C}-\mathrm{H}$ out of plane vibration. Existence of these bands in discharged cathode spectra indicates the presence of the $[\mathrm{B}(\mathrm{hfip})]^{-}$anion in the discharged cathode or formation of cathode passive layer from the decomposed salt (Figure S6). The charged cathode displays again well-defined $\mathrm{C}=\mathrm{O}$ and $\mathrm{C}-\mathrm{C}$ stretching bands together with the $\mathrm{C}-\mathrm{H}$ out of plane vibration, indicating a good reversibility of the electroactive group. Remaining of stretching bands between 1200 and $1000 \mathrm{~cm}^{-1}$ and $\mathrm{C}-\mathrm{F}$ vibration band in charged cathode indicate incomplete oxidation ( $88 \%$ according to capacity difference between discharge and charge) or the possible presence of decomposition products. 
a)
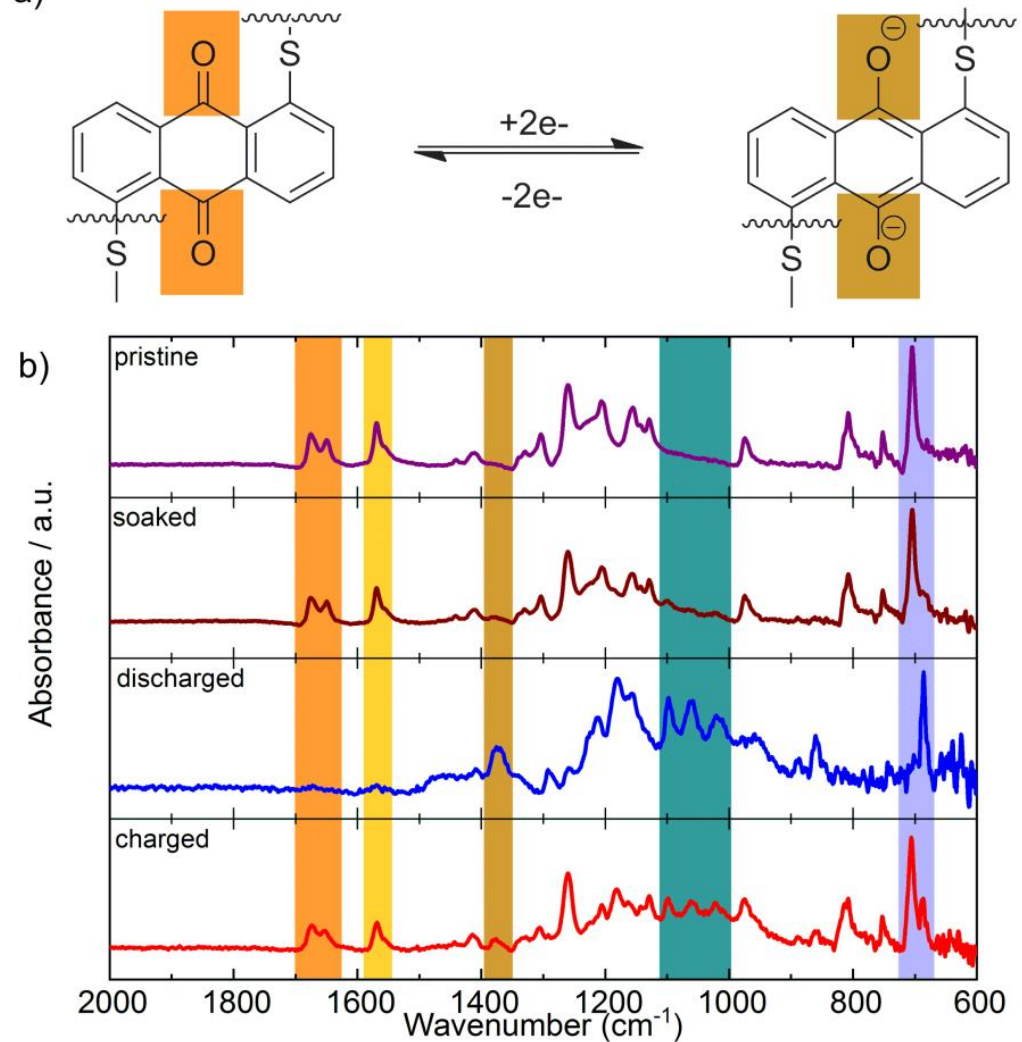

Figure 4: a) Electrochemical reaction of PAQS electrochemical group upon cell discharge. b) ATR-IR spectra of ex situ PAQS/CNTs electrodes. Pristine electrode (purple), electrode soaked in electrolyte and washed (brown), discharged electrode (blue) and charged electrode (red). The areas of the highest interest are shaded. Corresponding electrochemical data for discharged and charged electrode are presented in Figure S8.

Enabling $\mathrm{Ca}^{2+}$ storage is of utmost importance to achieve the high energy $\mathrm{Ca}$ metal-organic batteries, and the presence of monovalent cations $\left(\mathrm{Ca}\left[\mathrm{B}(\text { hfip })_{4}\right]^{+}\right)$as counter ions to the quinone groups in the reduced state would greatly decrease the energy density of our system and prevent cell operation in lean electrolyte conditions. ${ }^{[23,33]}$ We thus used SEM EDS to check the possible presence of $\left[\mathrm{B}(\mathrm{hfip})_{4}\right]^{-}$in the discharged compound.

\begin{tabular}{ccccccccc}
\hline Electrode & $\mathbf{C}$ & $\mathbf{O}$ & $\mathbf{F}$ & $\begin{array}{c}\text { F } \\
\text { active* }\end{array}$ & S & Cl & Ca & $\begin{array}{c}\text { mass } \\
\text { increase }\end{array}$ \\
\hline Pristine\&soaked & 35.72 & 2.88 & 3.61 & 0 & 1.00 & 0.16 & 0.03 & $3 \%$ \\
Discharged & 42.62 & 6.98 & 13.99 & 10.38 & 1.00 & 0.17 & 1.03 & $77 \%$ \\
Charged & 36.15 & 2.43 & 4.63 & 1.02 & 1.00 & 0.15 & 0.13 & $12 \%$ \\
\hline
\end{tabular}

Table 1: Atomic ratios of elements present in the electrodes, normalized per $S$ content. In the last column we report the relative increase of mass for specific electrodes. *Additional column $F$ active is introduced to differentiate between non-active F, which was present as PTFE binder and should remain constant through the electrochemical cycling, and active $F$, which was part of $B(h f i p) 4^{-}$anion. $F$ active was calculated after F content in pristine\&soaked electrode was subtracted from discharged and charged electrode. More details about the calculations are available in the SI. 
From the mass of the discharged electrode calculated from the EDS data (see SI for details about the calculation), we could clearly conclude that mass increase of $77 \%$ percent cannot be explained by exclusive formation of $\mathrm{PAQS}^{2}-\mathrm{Ca}^{2+}$ or $\mathrm{PAQS}^{2}-2\left[\mathrm{Ca}\left(\mathrm{B}(\mathrm{hfip})_{4}\right)^{+}\right]$in the discharged state. The former would, upon $100 \%$ PAQS capacity utilization, mean a mass increase of about $9 \%$, while the latter would mean an increase of mass of $326 \%$ due to the presence of two bulky $\left.\mathrm{Ca}\left[(\mathrm{B} \text { (hfip) })_{4}\right)\right]^{+}$cations. Thus, the most probable scenario is a majority of $\mathrm{PAQS}{ }^{2}-\mathrm{Ca}^{2+}$ species with a certain contribution of $\mathrm{PAQS}^{2}-2\left[\mathrm{Ca}\left(\mathrm{B}(\mathrm{hfip})_{4}\right)^{+}\right]$. In the discharged electrode, the significant increase in $\mathrm{F}$ content allows calculating the amount of $\mathrm{Ca}\left(\mathrm{B}(\mathrm{hfip})_{4}\right)^{+}$cation in the discharged cathode. From $\mathrm{F}$ and $\mathrm{Ca}$ content $\left(24 \mathrm{~F} \text { atoms per } \mathrm{Ca}\left[(\mathrm{B} \text { (hfip) })_{4}\right)\right]^{+}$cation), speciation of PAQS can be estimated and we calculate that in the discharge state there is $57 \% \mathrm{PAQS}^{2}-\mathrm{Ca}^{2+}, 21.5 \% \mathrm{PAQS}^{2}-2\left[\mathrm{Ca}\left(\mathrm{B}(\mathrm{hfip})_{4}\right)^{+}\right]$and $21.5 \%$ PAQS in molar ratios. From this assessment, we can estimate a discharged capacity of $177 \mathrm{mAh} / \mathrm{g}(172 \mathrm{mAh} / \mathrm{g}$ measured) and a mass increase of $75 \%$ (77\% measured), in excellent agreement with the measured values. Even though a non-negligible fraction of $\mathrm{Ca}\left(\mathrm{B}(\text { hfip })_{4}\right)^{+}$cations definitely takes part in the electrochemical reaction, most of the charge is still compensated by $\mathrm{Ca}^{2+}$ cations. EDS characterization of charged electrode shows us that incomplete charge (88\% according to capacities Figure S8) results also in increased $\mathrm{F}$ and $\mathrm{Ca}$ content in the charged electrode, but given the similar ratio between $\mathrm{F}$ and $\mathrm{Ca}$ in discharged and charged electrode, we can exclude preferential charging of the PAQS cathode.

While this study demonstrates the feasibility of a Ca-organic battery working at room temperature, opening for a sustainable direction for rechargeable Ca batteries, at the same time it shows the need for further development of stable electrolytes with anions that can weakly coordinate divalent cations. Properly designed electrolytes having high reductive stability, good efficiency for Ca stripping and deposition process and high dissociation constant for $\mathrm{Ca}$ salt are required for viable $\mathrm{Ca}$ batteries, including the $\mathrm{Ca}$-organic battery studied in this work.

\section{Conclusions}

The recent development of novel $\mathrm{Ca}$ electrolytes has enabled $\mathrm{Ca}$ stripping/deposition at room temperature. However, the development of Ca cathode materials is still lagging behind and is hindering the development of practical $\mathrm{Ca}$ rechargeable batteries. Herein, a proof-of-concept $\mathrm{Ca}$ metal-organic battery was proposed through application of organic polymer cathode. Good reversibility of $\mathrm{Ca}^{2+}$ insertion at the cathode was demonstrated, but after a few reversible cycles in a 2-electrode cell setup a big increase in overpotential resulted in a sudden drop of cell capacity. Application of 3-electrode cell allowed us to pin-point this overpotential to Ca metal anode during Ca stripping process. Reversibility of anthraquinone based cathode was confirmed through ex situ ATR-IR, where reversible reduction of carbonyl bond was observed upon discharge. The reduction of the carbonyl bond is compensated mainly by coordination with $\mathrm{Ca}^{2+}$ and in smaller part (less than $30 \%$ ) also by $\mathrm{Ca}\left(\mathrm{B}(\mathrm{hfip})_{4}\right)^{+}$ monovalent cation, as confirmed by ex situ EDS analyses. These results provide a very good base for the future development of organic electrodes for $\mathrm{Ca}$ batteries, suggesting that even higher degree of $\mathrm{Ca}^{2+}$ coordination in lean electrolyte setup can be obtained in improved conditions, but also states the need for detailed cathode characterization in the discharge state in future studies.

\section{Experimental section}

\section{Synthesis}

$\mathrm{Ca}[\mathrm{B} \text { (hfip) }]_{2} \times 4$ DME was synthesized similarly to the already published procedures ${ }^{[12,13]}$ (see SI for a detailed description). Poly (anthraquinoyl sulfide) (PAQS) was synthesized through polycondensation of 1,5dichloroanthraquinone with $\mathrm{Na}_{2} \mathrm{~S}$ according to the literature. ${ }^{[18]}$ In situ polymerization of PAQS was performed 
in a suspension of multi walled CNTs to improve conductivity and accessibility of electroactive groups, giving a composite denoted as PAQS/CNTs. ${ }^{[23]}$

\section{Material characterization}

Synthesis of the $\mathrm{Ca}[\mathrm{B} \text { (hfip) }]_{2} \times 4 \mathrm{DME}$ salt was verified through various complementary characterization techniques $\left({ }^{1} \mathrm{H},{ }^{11} \mathrm{~B},{ }^{13} \mathrm{C}\right.$ and ${ }^{19} \mathrm{~F}$ NMR, ATR-IR, powder X-ray diffraction (XRD), Raman spectroscopy, High resolution mass spectroscopy, ICP-OES). The formation of PAQS polymer was checked using ATR-IR. PAQS/CNTs composite polymer was characterized using FE SEM Supra 35 VP from Carl Zeiss at 3 kV.

\section{Electrochemical characterization}

Cathodes were prepared by mixing active material, Printex XE2 carbon black and PTFE binder in the ratio of 60:30:10. The mixture was ball milled with isopropanol using Retsch PM100 at $300 \mathrm{rpm}$. The composite was then put in agate mortar and ground until a "chewing gum"-like composite was obtained. Such electrode composite was rolled on a glass plate to obtain self-standing electrodes with loadings of active material of 2-3 $\mathrm{mg} / \mathrm{cm}^{2}$. The prepared electrodes were dried at $50{ }^{\circ} \mathrm{C}$ overnight and transferred inside an Ar-filled glove box.

Electrochemical characterization was performed in 2- and 3-electrode Swagelok cells assembled inside an Arfilled glove box. Ca shots (99.5\% Alfa Aesar) were shaped into $12 \mathrm{~mm}$ round discs and used as counter electrodes. A Ca disc was also used as the reference electrode in a 3-electrode cell. Glassy fiber Whatman GF/A sheets were used as separators. Electrolyte performance was assessed by cyclic voltammetry with a sweep rate of $25 \mathrm{mV} / \mathrm{s}$ on stainless steel working electrode. Electrochemical activity was tested using galvanostatic cycling with potential limitation. All the electrochemical tests were performed on WMP3 and MPG2 potentiostats from Bio Logic S. A.

\section{Ex situ electrode characterization}

Cells for the ex situ characterisation of the electrodes were disassembled inside the glove box after cycling. Electrodes were carefully removed from the cells and washed 3 times with $2 \mathrm{ml}$ of DME. Three types of separate electrodes (soaked with electrolyte, discharged and charged electrode) were prepared for ATR-IR analysis. ATRIR spectra were measured using a Bruker Alpha II spectrometer equipped with Ge crystal (several spots were measured, giving equivalent spectra) placed inside the glove box to prevent the degradation of samples. Ex situ electrodes were transferred to SEM chamber using specially designed sample holder in vacuum to prevent their decomposition in air. EDS characterization was performed on different electrode areas of at least $1 \mathrm{~mm}^{2}$ with a Oxford Instruments INCA EDS detector. The presented composition values represent the average of at least three different areas.

\section{Acknowledgements}

A.S. acknowledges ALISTORE-ERI for his PhD grant The authors would like to acknowledge financial support from Slovenian Research Agency under research project Z2-1864 and research program P2-0393, as well as French National Research Agency (ANR) under the public grant ANR-10-LABX-76-01 (Labex STOREX) as part of the "Investissements d'Avenir" program. The authors thank Edi Kranjc from National Institute of Chemistry for the capillary salt powder XRD acquisition. 


\section{References}

[1] J.-M. Tarascon, Nat. Chem. 2010, 2, 510.

[2] H. Kawamoto, W. Tamaki, Sci. Technol. Trends, Quart. Rev. 2011, 39, 51.

[3] M. M. Thackeray, C. Wolverton, E. D. Isaacs, Energy Environ. Sci. 2012, 5, 7854.

[4] D. Larcher, J.-M. Tarascon, Nat. Chem. 2014, 7, 19.

[5] A. Ponrouch, J. Bitenc, R. Dominko, N. Lindahl, P. Johansson, M. R. Palacin, Energy Storage Mater. 2019, $20,253$.

[6] M. Jäckle, K. Helmbrecht, M. Smits, D. Stottmeister, A. Groß, Energy Environ. Sci. 2018, 11, 3400.

[7] M. Matsui, J. Power Sources 2011, 196, 7048.

[8] M. E. Arroyo-De-Dompablo, A. Ponrouch, P. Johansson, M. R. Palacín, Chem. Rev. 2019, acs. chemrev.9b00339.

[9] R. J. Staniewicz, J. Electrochem. Soc. 1980, 127, 782.

[10] A. Ponrouch, C. Frontera, F. Bardé, M. R. Palacín, Nat. Mater. 2016, 15, 169.

[11] D. Wang, X. Gao, Y. Chen, L. Jin, C. Kuss, P. G. Bruce, Nat. Mater. 2018, 17, 16.

[12] Z. Li, O. Fuhr, M. Fichtner, Z. Zhao-Karger, Energy Environ. Sci. 2019, 12, 3496.

[13] A. Shyamsunder, L. E. Blanc, A. Assoud, L. F. Nazar, ACS Energy Lett. 2019, 4, 2271.

[14] D. S. Tchitchekova, C. Frontera, A. Ponrouch, C. Krich, F. Bardé, M. R. Palacín, Dalt. Trans. 2018, 47, 11298.

[15] D. S. Tchitchekova, A. Ponrouch, R. Verrelli, T. Broux, C. Frontera, A. Sorrentino, F. Bardé, N. Biskup, M. E. Arroyo-de-Dompablo, M. R. Palacín, Chem. Mater. 2018, 30, 847.

[16] A. L. Lipson, S.-D. Han, S. Kim, B. Pan, N. Sa, C. Liao, T. T. Fister, A. K. Burrell, J. T. Vaughey, B. J. Ingram, J. Power Sources 2016, 325, 646.

[17] C. R. Deblase, K. Hernández-Burgos, J. M. Rotter, D. J. Fortman, D. Dos S. Abreu, R. A. Timm, I. C. N. Diógenes, L. T. Kubota, H. D. Abruña, W. R. Dichtel, Angew. Chem. Int. Ed. 2015, 54, 13225.

[18] Z. Song, H. Zhan, Y. Zhou, Chem. Commun. 2009, 448.

[19] C. Guo, K. Zhang, Q. Zhao, L. Pei, J. Chen, Chem. Commun. 2015, 51, 10244.

[20] Z. Jian, Y. Liang, I. A. R. Pérez, Y. Yao, X. Ji, Electrochem. Commun. 2016, 71, 5.

[21] J. Bitenc, K. Pirnat, T. Bančič, M. Gaberšček, B. Genorio, A. R. Vitanova, R. Dominko, ChemSusChem 2015, 8, 4128.

[22] B. Häupler, C. Rössel, A. M. Schwenke, J. Winsberg, D. Schmidt, A. Wild, U. S. Schubert, NPG Asia Mater. 2016, 8, e283.

[23] J. Bitenc, N. Lindahl, A. Vizintin, M. E. Abdelhamid, R. Dominko, P. Johansson, Energy Storage Mater. 2020, 24, 379 .

[24] T. B. Schon, B. T. McAllister, P.-F. Li, D. S. Seferos, Chem. Soc. Rev. 2016, 45, 6345. 
[25] J. Bitenc, K. Pirnat, E. Žagar, A. Randon-Vitanova, R. Dominko, J. Power Sources 2019, 430, 90.

[26] Z. Song, Y. Qian, M. L. Gordin, D. Tang, T. Xu, M. Otani, H. Zhan, H. Zhou, D. Wang, Angew. Chem. 2015, 127, 14153.

[27] I. A. Rodríguez-Pérez, Y. Yuan, C. Bommier, X. Wang, L. Ma, D. P. Leonard, M. M. Lerner, R. G. Carter, T. Wu, P. A. Greaney, J. Lu, X. Ji, J. Am. Chem. Soc. 2017, 139, 13031.

[28] S. Gheytani, Y. Liang, F. Wu, Y. Jing, H. Dong, K. K. Rao, X. Chi, F. Fang, Y. Yao, Adv. Sci. 2017, 4, 1700465.

[29] H. Hagemann, R. Černý, Dalt. Trans. 2010, 39, 6006.

[30] Z. Zhao-Karger, M. E. Gil Bardaji, O. Fuhr, M. Fichtner, J. Mater. Chem. A 2017, 5, 10815.

[31] A. Vizintin, J. Bitenc, A. Kopač Lautar, K. Pirnat, J. Grdadolnik, J. Stare, A. Randon-Vitanova, R. Dominko, Nat. Commun. 2018, 9, 661.

[32] J. Bitenc, T. Pavčnik, U. Košir, K. Pirnat, Materials (Basel). 2020, 13, 506.

[33] H. Dong, Y. Liang, H. Dong, Y. Liang, O. Tutusaus, R. Mohtadi, Y. Zhang, F. Hao, Y. Yao, Joule 2019, 1. 